\title{
Late Presentation to Care among People Living with HIV in Cotonou, Benin: A Retrospective Analysis from 2003 to 2014
}

\author{
Djimon Marcel Zannou1,2, Pacos Bray Gandaho ${ }^{2 *}$, Angèle Azon-Kouanou 1,2, Carin Ahouada ${ }^{1,2}$, \\ Kuessi Anthelme Agbodande1, Armand Wanvoegbe', Jocelyn Akakpo², Fabien Houngbe ${ }^{1}$ \\ ${ }^{1}$ Department of Internal Medicine, National Teaching Hospital Hubert K. Maga (CNHU-Hubert K. Maga), Cotonou, Benin \\ ${ }^{2}$ National Referral Center for HIV Research and Comprehensive Care at CNHU-Hubert K. Maga, Cotonou, Benin \\ Email: *gandahobp@gmail.com
}

How to cite this paper: Zannou, D.M., Gandaho, P.B., Azon-Kouanou, A., Ahouada, C., Agbodande, K.A., Wanvoegbe, A., Akakpo, J. and Houngbe, F. (2017) Late Presentation to Care among People Living with HIV in Cotonou, Benin: A Retrospective Analysis from 2003 to 2014. Open Journal of Internal Medicine, 7, 123-134. https://doi.org/10.4236/ojim.2017.74013

Received: September 4, 2017

Accepted: November 13, 2017

Published: November 16, 2017

Copyright (C) 2017 by authors and Scientific Research Publishing Inc. This work is licensed under the Creative Commons Attribution International License (CC BY 4.0).

http://creativecommons.org/licenses/by/4.0/

\begin{abstract}
Background: Late presentation to care is associated with increased morbidity, mortality and healthcare cost. Objectives: To determine the prevalence of late presentation to care in Benin, describe its trends and identify risk factors associated. Methods: We conducted a retrospective analysis from 2003 to 2014 at the National HIV Referral Centre in Benin. The definition of the European Late Presentation Consensus Group (ELPCG) for late presentation to care was used. Late Presenters (LP) were defined as patients presenting to care with CD4 count below 350 cells $/ \mathrm{mm}^{3}$ or with an AIDS defining event, and patients with advanced HIV disease (AHD) were defined as persons with a CD4 count below 200 cells $/ \mathrm{mm}^{3}$. Results: 5018 patients were included. Women accounted for 62.9\%. Patients ranged in age from 18 to 62 years. 4233 patients (84.4\%) were late presenters (LP) and 3126 (62.3\%) were in Advanced HIV Disease (AHD). Late presentation decreased from $97.7 \%$ in 2003 to $78.7 \%$ in 2009. Between 2009 and 2014, there was no substantial decrease. Older age [Odds Ratio (OR) $=3.17$; 95\% Confidence Interval $(\mathrm{CI})=[2.52-4.00], \mathrm{p}<0.001]$, male gender $(\mathrm{OR}=1.85 ; 95 \% \mathrm{CI}=[1.56-2.22], \mathrm{p}<0.001)$ and non-schooling $(\mathrm{OR}=2.13$; $95 \%$ CI [1.77 - 2.56], $\mathrm{p}<0.001)$, were associated with late presentation to care. Being diagnosed through the Prevention of Mother To Child Transmission (PMTCT) of HIV, appeared as a protective factor (OR $=0.20$; 95\% CI $[0.15$ 0.27], $\mathrm{p}<0.001$ ). Conclusions: The prevalence of late presentation to care in Cotonou is alarming. This prevalence has been on a declining trend, but it remains extremely high. In order to reach the first 90 of the 90-90-90 targets, policymakers should promote the Provider-initiated HIV Testing and Counselling in all health facilities, modeled on the existing PMTCT of HIV screening during pregnancy.
\end{abstract}




\section{Keywords}

Late Presentation, HIV, European Consensus, Benin

\section{Introduction}

Late presentation to care among HIV infected people is associated with greater morbidity and mortality, lower treatment response and increased treatment costs [1]. Late presenters to care have higher risk of HIV-transmission since they cannot adopt risk reduction precautions or lower their viral load as a result of Antiretroviral Therapy [2].

The term "late presentation" is used in many studies to refer to individuals with HIV infection who presented for clinical care at late stages of infection [3]. However, many definitions have been used to assess its burden in many setting [4]. It has been defined using either CD4 count or WHO clinical stage by different authors but sometimes, both were used [5]. As the chosen definition had an impact on the apparent prevalence of late presentation, studies from high income countries reported less than $30 \%$ of late presenters [6], whereas in sub-Saharan Africa this proportion was between $60 \%$ and $80 \%$ [7]. To fix that issue and make it possible to compare the outcomes from different studies, the European Late Presentation Consensus working Group (ELPCG) has released an unique definition for the late presentation to HIV-care in 2011 [8]. The main advantage of this consensus definition was that it provides an unified way to define the problem by associating the CD4 count and the WHO clinical stage [9].

In developed countries across the world, this consensus definition was used in many studies [10] [11]. Instead, in African countries, despite the high burden of HIV infection, this definition has rarely been used [12]. Also, it is proved that many factors were associated with late presentation to care. Factors associated with late presentation include age, gender, unemployment, having lower education level, stigma, nondisclosure of the HIV infection, long distance to health facilities. Other includes the year of presentation and the reason for screening. Unless we reduce these factors, earlier initiation of HIV treatment cannot be possible.

The aims of this study were to determine the prevalence of late presentation to care among people living with HIV in Cotonou, to describe the trends in late presentation, and to identify the factors associated with it, by using the European consensus definition.

\section{Methods}

We carried out a retrospective analysis using the medical records of all patients initially presenting for care at the National Referral Centre for HIV Research and Comprehensive Care in Benin, between January 2003 and December 2014. All data were extracted from the ESOPE database. We performed an exhaustive 
sampling of the HIV-infected patients aged more than 18 years, who have never experienced the Antiretroviral Therapy before their first visit. Only patients with initial WHO clinical stage and initial CD4 count available at the first visit or before ART initiation were included. Data abstracted were socio-demographic (gender, age, educational level, occupation, marital status, location), circumstances of HIV testing, Type of HIV virus, Date of first presentation to care, Weight, Height, Clinical features, WHO clinical stage, first CD4 count.

The outcome variable was the late presentation to care. We used the definition of the European Late Presenters Consensus working Group [8]. According with this definition, we made a distinction of late presenters using two dependent variables:

Late presenters (LP) were patients presenting for care with a CD4 count $<350$ cells/ $\mu \mathrm{L}$ or presenting with an AIDS-defining event, regardless of the CD4 count.

Late presenters with Advanced HIV Disease (AHD) were patients presenting for care with a CD 4 count $<200$ cells $/ \mu \mathrm{L}$ or presenting with an AIDS defining event.

The following exposure variables were considered: gender, age, educational level, occupation, marital status, location, circumstances of HIV testing, Body Mass Index (BMI), year of first presentation to care. Statistical analyses were performed with STATA/IC software version 11.0. The numerical variables were expressed as medians and Inter quartile Ranges (IQR) and categorical variables were expressed in terms of frequencies. Univariate and multivariate analysis for factors associated with late presentation were performed. In univariate analysis, numerical variables were compared using the $\mathrm{t}$-test and categorical variables were compared using Chi-Square tests. Multivariate analysis was conducted employing logistic regression models. Candidate variables for multivariate analysis were those that showed an association with late presentation with a p-value $\leq 0.20$ in the univariate analysis. Odds ratio (OR) with $95 \%$ confidence intervals $\left(\mathrm{CI}_{(95 \%)}\right)$ was used to estimate the magnitude of the association between exposure variables and late presentation to care. All p-values less than 0.05 were considered statistically significant.

\section{Results}

Among 5212 HIV-positive patients admitted at the National Referral Center for HIV Research and Comprehensive Care between January 2003 and December 2014, 5018 patients were eligible for our analysis.

\subsection{General Characteristics}

Out of the 5018 patients, 3158 (62.9\%) were women as presented in Table 1. The median age was 37 years (IQR: 18 - 62 years) and $642(12.8 \%)$ patients were older than 50 years. The majority of the patients 1938 (58.9\%) were married and $38.6 \%$ attended secondary school or higher. 4276 (85.2\%) patients were living in Cotonou or nearby. The HIV testing was mainly performed due to clinical suspicion 
Table 1. General characteristics of HIV-infected people at presentation to care, $\mathrm{n}=5018$.

\begin{tabular}{|c|c|c|}
\hline & Frequency $(n=5018)$ & Percentage (\%) \\
\hline \multicolumn{3}{|l|}{ Gender } \\
\hline Female & 3158 & 62.9 \\
\hline Male & 1860 & 37.1 \\
\hline \multicolumn{3}{|l|}{ Age (years) } \\
\hline$<30$ & 1214 & 24.2 \\
\hline $30-39$ & 1952 & 38.9 \\
\hline $40-49$ & 1210 & 24.1 \\
\hline$\geq 50$ & 642 & 12.8 \\
\hline \multicolumn{3}{|l|}{ Occupation } \\
\hline Handworker & 2295 & 45.8 \\
\hline Public employee & 708 & 14.1 \\
\hline Commerce & 1455 & 29.0 \\
\hline Unemployed & 560 & 11.2 \\
\hline \multicolumn{3}{|l|}{ Marital status } \\
\hline Married & 2956 & 58.9 \\
\hline Single & 699 & 13.9 \\
\hline Widowed & 1064 & 21.2 \\
\hline Unknown & 299 & 6.0 \\
\hline \multicolumn{3}{|l|}{ Education } \\
\hline Secondary or higher & 1938 & 38.6 \\
\hline Primary or none & 1423 & 28.4 \\
\hline Unknown & 1657 & 33.0 \\
\hline \multicolumn{3}{|l|}{ Location } \\
\hline Cotonou or nearby & 4276 & 85.2 \\
\hline Other & 742 & 14.8 \\
\hline
\end{tabular}

of HIV for 3712 (74\%) patients. The BMI was lower than $18.5 \mathrm{~kg} / \mathrm{m}^{2}$ for 2966 (59.1\%) patients. HIV-1 was the leading type of HIV virus found among them (92\%). 3753 (74.8\%) presented to care with WHO Clinical stage 4 and 3288 (65.6\%) had CD4 count lower than 200 cells/ $\mu \mathrm{L}$. The proportion of patients with a CD4 cell count $<350$ cells $/ \mu \mathrm{L}$ was $78.6 \%$. The median CD4 count at presentation was 192.3 cells/ $\mu \mathrm{L}$ (IQR: 47 - 223). The number of patients by years was not the same for the 12 years. As presented in Table 2, the year 2009 was the most represented with 613 patients and the year 2003 was the less represented with 221 patients. 
Table 2. Prevalence of late presentation and advanced HIV disease by year, 2003 to 2014 , Cotonou.

\begin{tabular}{ccccccc}
\hline & \multicolumn{2}{c}{ Total } & \multicolumn{2}{c}{ Late Presentation } & \multicolumn{2}{c}{ Advanced HIV Disease } \\
\cline { 2 - 6 } & Frequency & $\%$ & Frequency & $\%$ & Frequency & $\%$ \\
\hline $\mathbf{2 0 0 3}$ & 221 & 4.4 & 216 & 97.7 & 196 & 88.7 \\
$\mathbf{2 0 0 4}$ & 414 & 8.3 & 403 & 97.3 & 371 & 89.6 \\
$\mathbf{2 0 0 5}$ & 529 & 10.5 & 492 & 93.0 & 427 & 80.7 \\
$\mathbf{2 0 0 6}$ & 357 & 7.1 & 315 & 88.2 & 230 & 64.4 \\
$\mathbf{2 0 0 7}$ & 379 & 7.6 & 315 & 83.1 & 227 & 59.9 \\
$\mathbf{2 0 0 8}$ & 415 & 8.3 & 339 & 81.7 & 218 & 52.5 \\
$\mathbf{2 0 0 9}$ & 613 & 12.2 & 476 & 77.7 & 306 & 49.9 \\
$\mathbf{2 0 1 0}$ & 511 & 10.2 & 412 & 80.6 & 262 & 51.3 \\
$\mathbf{2 0 1 1}$ & 354 & 7.1 & 293 & 82.8 & 204 & 57.6 \\
$\mathbf{2 0 1 2}$ & 393 & 7.8 & 311 & 79.1 & 221 & 56.2 \\
$\mathbf{2 0 1 3}$ & 431 & 8.6 & 358 & 83.1 & 258 & 59.9 \\
$\mathbf{2 0 1 4}$ & 401 & 7.9 & 303 & 75.6 & 208 & 51.9 \\
Total & $\mathbf{5 0 1 8}$ & $\mathbf{1 0 0}$ & $\mathbf{4 2 3 3}$ & $\mathbf{8 4 . 4}$ & $\mathbf{3 1 2 8}$ & $\mathbf{6 2 . 3}$ \\
\hline
\end{tabular}

\subsection{Prevalence of Late Presentation to Care and Advanced HIV Disease}

The prevalence of late presentation (LP) was $84.4 \%$ (4233 patients out of 5018) and that of Advanced HIV Disease (AHD) was 62.3\% (3128 patients out of 5018) for all the 12 years of the study (Table 2).

\subsection{Trends in LP and AHD}

The trends of the proportion of patients presenting late to care and those presenting to care with Advanced HIV Disease is presented on Table 2. First the prevalence has decreased during the 12 years. Secondly, we find out that from 2003 to 2009 , the prevalence decreased from $97.7 \%$ to $77.7 \%$ for the late presentation and from $88.7 \%$ to $49.9 \%$ for the late presentation with Advanced HIV Disease. Between 2009 and 2014, the proportion has remained stable around $80 \%$ for late presentation and $50 \%$ for AHD.

\subsection{Factors Associated with Late Presentation to Care}

The factors associated with late presentation to care are presented in Table 3.

Patients aged more than 50 years [Odds Ratio (OR): 3.19; 95\% Confidence Interval (CI): $2.32-4.14$ ] and those between 40 and 49 years (OR: 3.17; 95\% CI: 2.52 - 4.00) were at higher risk of late presentation to care compared to those aged < 30 years. Compared to women, men (OR: 1.85, CI: $1.56-2.22$ ) were more likely to present to care later. Not educated patients (OR: 2.13, CI: $1.77-2.56$ ) were more likely to present late to care compared to educated. Patients without 
Table 3. Factors associated with late presentation in Cotonou, Benin, 2003 to 2014.

\begin{tabular}{|c|c|c|c|c|c|}
\hline & \multirow{2}{*}{ Frequency (\%) } & \multicolumn{2}{|c|}{ Unadjusted } & \multicolumn{2}{|c|}{ Adjusted } \\
\hline & & $\mathrm{OR}\left[\mathrm{CI}_{(95 \%)}\right]$ & $\mathrm{p}$ value & $\operatorname{AOR}\left[\mathrm{CI}_{(95 \%)}\right]$ & $\mathrm{p}$ value \\
\hline Gender & & & $<0.001$ & & \\
\hline Female & $2576(81.6)$ & 1 & & & \\
\hline Male & $1657(89.1)$ & $1.85[1.56-2.22]$ & & & \\
\hline Age (years) & & & $<0.001$ & & $<0.001$ \\
\hline$<30$ & $908(74.8)$ & 1 & & 1 & \\
\hline $30-39$ & $1652(84.6)$ & $1.85[1.55-2.21]$ & & $1.89[1.54-2.33]$ & \\
\hline $40-49$ & $1094(90.4)$ & $3.17[2.52-4.00]$ & & $3.19[2.46-4.16]$ & \\
\hline$>50$ & $579(90.2)$ & $3.19[2.32-4.14]$ & & $3.55[2.46-4.93]$ & \\
\hline Education level & & & $<0.001$ & & \\
\hline Secondary or higher & $1221(85.8)$ & 1 & & & \\
\hline Primary or none & $1715(88.5)$ & $2.13[1.77-2.56]$ & & & \\
\hline Unknown & $1297(78.3)$ & $1.67[1.38-2.03]$ & & & \\
\hline Occupation & & & 0.008 & & \\
\hline Handworker & $1971(85.9)$ & 1 & & & \\
\hline Public employee & $604(85.3)$ & $0.95[0.75-1.21]$ & & & \\
\hline Commerce & $1204(82.8)$ & $0.79[0.66-0.94]$ & & & \\
\hline Unemployed & $454(81.1)$ & $0.70[0.55-0.90]$ & & & \\
\hline Marital status & & & $<0.001$ & & \\
\hline Married & $2489(84.2)$ & 1 & & & \\
\hline Single & $572(81.8)$ & $0.85[0.68-1.05]$ & & & \\
\hline Widowed & $953(89.6)$ & $1.61[1.29-2.01]$ & & & \\
\hline Unknown & $219(73.2)$ & $0.51[0.39-0.68]$ & & & \\
\hline Location & & & 0.277 & & \\
\hline Cotonou or nearby & $3617(84.6)$ & 1 & & & \\
\hline Other & $492(83.4)$ & $0.89[0.72-1.09]$ & & & \\
\hline Reason for testing & & & $<0.001$ & & \\
\hline PMTCT & $160(62.0)$ & 1 & & & \\
\hline Clinical suspicion & $3296(88.8)$ & $4.85[3.70-6.37]$ & & & \\
\hline Blood born & $402(63.7)$ & $1.08[0.80-1.45]$ & & & \\
\hline Own initiative & $375(89.9)$ & $4.95[3.63-6.70]$ & & & \\
\hline BMI $\left(\mathrm{kg} / \mathrm{m}^{2}\right)$ & & & $<0.001$ & & $<0.001$ \\
\hline$<18.5$ & $2966(91.6)$ & $1.67[1.10-2.55]$ & & $1.85[1.16-2.95]$ & \\
\hline $18.5-25$ & $1328(86.7)$ & 1 & & 1 & \\
\hline $25-30$ & $292(77.0)$ & $0.51[0.38-0.68]$ & & $0.49[0.35-0.67]$ & \\
\hline$>30$ & $75(52.8)$ & $0.17[0.12-0.25]$ & & $0.18[0.11-0.27]$ & \\
\hline
\end{tabular}


an occupation (OR: $0.70, \mathrm{CI}: 0.55-0.90, \mathrm{p}=0.008$ ) were less likely to present late to care than those with a profession. The location was not associated with late presentation in our study. The reason for HIV screening was significantly associated with late presentation to care. Patients screened after clinical suspicion for HIV were 5 times more likely (OR: 4.85, CI: $3.70-6.37, \mathrm{p}<0.001$ ) to be late presenters compared to screening during PMTCT. Another key finding was that the year of presentation to care was also associated with late presentation. In 2003 (OR: 13.97, CI: 5.59 - 34.89, p < 0.001) and 2004(OR: 11.84, CI: 6.24 - 22.49, $\mathrm{p}<0.001)$, patients were respectively 14 and 12 time more likely to be late presenters to care than those presenting to care in 2014.

In multivariate analysis, age, BMI and year of presentation to care were predictive factors for late presentation to care. (Table 4)

\section{Discussion}

\subsection{Prevalence of Late Presentation}

In our study, $84.4 \%$ of HIV-infected people were late presenters and $62.3 \%$ were late presenters with Advanced HIV Disease. This high proportion of late presentation was similar to the $85.4 \%$ for late presentation and $63.0 \%$ for Advance HIV Disease reported from Nigeria in 2013 [12]. However it was higher than that obtained from European studies, where it varied from $48.1 \%$ to $55.2 \%$ for Late Presentation and from $29.4 \%$ to $37.8 \%$ for Advanced HIV Disease [13] [14] [15]. In Benin as well as in other African countries, the issue of late presentation to care is not a restricted HIV concern. It is common with many diseases and is caused by the social and cultural behaviors toward diseases, financial constraints and faith in spiritual treatments [16] [17]. Patients usually seek care from healers first and they only go to hospitals when advanced stages of their diseases are reached [17]. As far as HIV is concerned, stigma, being unaware of HIV-status could also explain these results [18]. Since we performed a retrospective data analysis, we could not assess whether these factors were involved in our study. We could not also explain if there were a delay between the first HIV positive test and the first presentation to care. Actually, it is possible that many of these patients were unaware of their HIV status prior to their presentation care and there were no delay due to the patient himself [19]. Then, the issue to make people infected with HIV be aware of their status earlier is important.

\subsection{Trends in the Prevalence of Late Presentation}

The burden of late presentation has decreased throughout the 12 years of our study, and patients are presenting earlier to care. This finding was similar to the reports from Nigeria [12]. The changes in guidelines to initiate HIV treatment and the continuous screening campaigns have probably been part of the downward trend. But one important finding from our results was that after 2009, the prevalence was more likely to stabilize around $80 \%$. There was no statistical difference between the prevalence of late presentation from 2009 to 2014 . This means 
Table 4. Association between late presentation and year of presentation to care.

\begin{tabular}{|c|c|c|c|c|c|}
\hline \multicolumn{2}{|c|}{ Frequency (\%) } & \multicolumn{2}{|c|}{ Unadjusted } & \multicolumn{2}{|c|}{ Adjusted } \\
\hline & & $\mathrm{OR}\left[\mathrm{CI}_{(95 \%)}\right]$ & $\mathrm{p}$ value & $\mathrm{AOR}\left[\mathrm{CI}_{(95 \%)}\right]$ & $\mathrm{p}$ value \\
\hline \multicolumn{2}{|l|}{ Years } & \multicolumn{3}{|c|}{$<0.001$} & $<0.001$ \\
\hline 2003 & $216(97.74)$ & $13.97[5.59$ - 34.89] & & $15.65[6.06-40.44]$ & \\
\hline 2004 & $403(97.34)$ & $11.84[6.24-22.49]$ & & $9.53[4.84-18.77]$ & \\
\hline 2005 & $492(93.01)$ & $4.30[2.87-6.44]$ & & $4.15[2.64-6.52]$ & \\
\hline 2006 & $315(88.24)$ & $2.42[1.63-3.59]$ & & $2.30[1.47-3.60]$ & \\
\hline 2007 & $315(83.11)$ & $1.59[1.12-2.26]$ & & $1.96[1.30-2.97]$ & \\
\hline 2008 & $339(81.69)$ & $1.44[1.02-2.02]$ & & $1.67[1.13-2.47]$ & \\
\hline 2009 & $476(77.65)$ & $1.12[0.83-1.51]$ & & $1.32[0.93-1.87]$ & \\
\hline 2010 & $412(80.63)$ & $1.34[0.98-1.84]$ & & $1.47[1.01-2.13]$ & \\
\hline 2011 & $293(82.77)$ & $1.55[1.08-2.22]$ & & $1.83[1.21-2.76)$ & \\
\hline 2012 & $311(79.13)$ & $1.22[0.88-1.71]$ & & $0.98[0.67-1.45]$ & \\
\hline 2013 & $358(83.06)$ & $1.58[1.12-2.22]$ & & $1.52[1.02-2.25]$ & \\
\hline 2014 & $303(75.56)$ & 1 & & 1 & \\
\hline
\end{tabular}

that an important effort should be made to tackle the factors which have never been addressed until now. If this is not done the prevalence will still so high for the upcoming years.

\subsection{Factors Associated with Late Presentation}

Our results suggested that people aged more than 40 years were 3 times more likely to be late presenters than those under 30 years. Similar results were also found by Jeong et al. [20]. The reason is that the screening campaigns that were carried out targeted mainly young people and offered very little opportunities for old people to be screened early. The reason was that old people were perceived to be at lower risks of being HIV-positive, but they were often infected when they were young and the diagnosis was not made [21]. Moreover, practitioners performed HIV screening for young people than elders when they are hospitalized. This confirms the relevant role of healthcare professionals in recommending HIV testing not only in presence of AIDS-defining events but also without any particular symptom.

Late presentation was higher among men than women, raising the fact that men had fewer opportunities to be tested for HIV than women [22]. Basically, on behalf of the Prevention of Mother-to-Child Transmission (PMTCT) of HIV, systematic screening for HIV was offered to every woman when they were pregnant [23]. When pregnant women were HIV-positive, they were more willing to seek HIV-care early because of the risk of transmission to their child [24]. This explanation is emphasized by our results about the reason for HIV testing, showing that patients diagnosed by clinical suspicion were 5 times more likely to be 
late presenters than those diagnosed through PMTCT [23] [25].

The risk of late presentation was higher for the patients with educational level lower than secondary. Wilson and Hoffmann made the same observation in their studies in 2014 [7] [26]. This observation could be explained by the fact that outreach campaigns, were more understandable for those who were enrolled in school and they were therefore screened earlier [27].

Location was not associated to late presentation in our study. There was no statistical difference between the prevalence of late presentation for patients who were living in Cotonou and those who were living in other cities. This finding is important since it make it clear that the distance to the HIV center and its accessibility are not the issues leading to late presentation. However, in Kenya, Kwobah found that the distance to the health facility was an important factor for late presentation [18]. In this study, the authors considered late presenters as those who presented to care with CD 4 cell count $\leq 100$ cells $/ \mu \mathrm{L}$. This is probably the reason that explains the differences.

The risk of delaying care when patients were diagnosed with clinical suspicion was 5 times that of PMCT patients. This means that the systematic screening offered to pregnant women for PMTCT is very beneficial for early presentation to care. This practice should therefore be extended beyond the PMTCT framework to all medical consultations so that HIV testing will be offered to anyone who has contact with a health facility. That is known under the name Provider-Initiated HIV Testing and Counselling (PITC).

For the year of presentation to care, patients seen in 2003 and 2004 were 12 and 14 times late presenters than those seen in 2014. This could be explained by the fact that in 2003 and 2004, there was no evidence about the necessity to start earlier the antiretroviral treatment [28]. Furthermore, screening was only based on clinical features and late presentation risk was higher during these years.

One major limitation of this study was the retrospective data collection method. As a fact of matter, it was not possible to assess whether prior knowledge of HIV played a relevant role in late presentation to care. Those who had prior knowledge of the importance of early HIV screening may be willing to seek care earlier than those who had not. But we were not able to assess it. Another backside of the retrospective method was that with this method, we had to deal with missing data for several patients. Also, the CD4 count can be reduced by many opportunistic diseases even though the patient presented earlier to care. Then the definition of late presentation will not be so accurate that it should be. So, regardless of the fact that the definition of the ELPCG was the most commonly used, it exposed our findings to an information bias due to the fact that opportunistic diseases can lower the CD4 count.

\section{Conclusion}

Late presentation to care among people living with HIV was assessed in this study with the European Late Presentation consensus definition. Our results suggest that the overall prevalence of late presentation in Benin is alarming. This 
prevalence has been on a downward trend through the 12 years of the study, but it remains extremely high. Being older in age, of male gender and lower educated are associated with late presentation to care in Benin. Being diagnosed during pregnancy through PMTCT was a protective factor against late presentation to care. The priority for all stakeholders should be to implement a strategy aiming to encourage earlier HIV diagnosis in order to achieve the first 90 of the 90-90-90 targets of UNAIDS. We suggest that policymakers should promote the provider-initiated HIV testing and counselling in all health facilities of the country, modeled on the existing HIV screening during pregnancy.

\section{Conflicts of Interest}

The authors declared no potential conflicts of interest with respect to the research, authorship, and publication of this article.

\section{References}

[1] Krentz, H.B. and Gill, M.J. (2012) The Direct Medical Costs of Late Presentation $(<350 / \mathrm{Mm})$ of HIV Infection over a 15-Year Period. AIDS Research and Treatment, 2012, Article ID: 757135. https://doi.org/10.1155/2012/757135

[2] Liu, H., Su, Y., Zhu, L., Xing, J., Wu, J. and Wang, N. (2014) Effectiveness of ART and Condom Use for Prevention of Sexual HIV Transmission in Serodiscordant Couples: A Systematic Review and Meta-Analysis. PloS One, 9, 111175. https://doi.org/10.1371/journal.pone.0111175

[3] Jiang, H., Xie, N., Liu, J., Zhang, Z., Liu, L., Yao, Z., et al. (2015) Late HIV Diagnosis: Proposed Common Definitions and Associations with Short-Term Mortality. Medicine, 94, 1511. https://doi.org/10.1097/MD.0000000000001511

[4] Waters, L. and Sabin, C.A. (2011) Late HIV Presentation: Epidemiology, Clinical Implications and Management. Expert Review of Anti-Infective Therapy, 9, 877-889. https://doi.org/10.1586/eri.11.106

[5] Adler, A., Mounier-Jack, S. and Coker, R.J. (2009) Late Diagnosis of HIV in Europe: Definitional and Public Health Challenges. AIDS Care, 21, 284-293. https://doi.org/10.1080/09540120802183537

[6] Battegay, M., Fehr, J., Flückiger, U. and Elzi, L. (2008) Antiretroviral Therapy of Late Presenters with Advanced HIV Disease. The Journal of Antimicrobial Chemotherapy, 62, 41-44. https://doi.org/10.1093/jac/dkn169

[7] Hoffman, S., Wu, Y., Lahuerta, M., Kulkarni, S.G., Nuwagaba-Biribonwoha, H., Sadr, W.E., et al. (2014) Advanced Disease at Enrollment in HIV Care in Four Sub-Saharan African Countries: Change from 2006 to 2011 and Multilevel Predictors in 2011. AIDS (London, England), 28, 2429-2438. https://doi.org/10.1097/QAD.0000000000000427

[8] Antinori, A., Coenen, T., Costagiola, D., Dedes, N., Ellefson, M., Gatell, J., et al. (2011) Late Presentation of HIV Infection: A Consensus Definition. HIV Medicine, 12, 61-64. https://doi.org/10.1111/j.1468-1293.2010.00857.x

[9] UK Collaborative HIV Cohort (UK CHIC) Steering Committee, Sabin, C.A., Schwenk, A., Johnson, M.A., Gazzard, B., Fisher, M., et al. (2010) Late Diagnosis in the HAART Era: Proposed Common Definitions and Associations with Mortality. AIDS (London, England), 24, 723-727. 
[10] Dickson, N., McAllister, S., Sharples, K. and Paul, C. (2012) Late Presentation of HIV Infection among Adults in New Zealand: 2005-2010. HIV Medicine, 13, 182-189.

[11] Drain, P.K., Losina, E., Parker, G., Giddy, J., Ross, D., Katz, J.N., et al. (2013) Risk Factors for Late-Stage HIV Disease Presentation at Initial HIV Diagnosis in Durban, South Africa. PLoS ONE, 8, 55305. https://doi.org/10.1371/journal.pone.0055305

[12] Agaba, P.A., Meloni, S.T., Sule, H.M., Agbaji, O.O., Ekeh, P.N., Job, G.C., et al. (2014) Patients Who Present Late to HIV Care and Associated Risk Factors in Nigeria. HIV Medicine, 15, 396-405. https://doi.org/10.1111/hiv.12125

[13] Camoni, L., Raimondo, M., Regine, V., Salfa, M.C. and Suligoi, B. (2013) Late Presenters among Persons with a New HIV Diagnosis in Italy, 2010-2011. BMC Public Health, 13, 281. https://doi.org/10.1186/1471-2458-13-281

[14] Metallidis, S., Pilalas, D., Skoura, L., Haidich, A.-B., Tsachouridou, O., Papaioannou, M., et al. (2012) Time Trends and Correlates of Late Presentation for HIV Care in Northern Greece during the Decade 2000 to 2010. Journal of the International AIDS Society, 15.

[15] Oliva, J., Díez, M., Galindo, S., Cevallos, C., Izquierdo, A., Cereijo, J., et al. (2014) Predictors of Advanced Disease and Late Presentation in New HIV Diagnoses Reported to the Surveillance System in Spain. Gaceta Sanitaria, 28, 116-122.

[16] Bonjour, M.A., Montagne, M., Zambrano, M., Molina, G., Lippuner, C., Wadskier, F.G., et al. (2008) Determinants of Late Disease-Stage Presentation at Diagnosis of HIV Infection in Venezuela: A Case-Case Comparison. AIDS Research and Therapy, 5, 6. https://doi.org/10.1186/1742-6405-5-6

[17] Parrott, F.R., Mwafulirwa, C., Ngwira, B., Nkhwazi, S., Floyd, S., Houben, R.M.G.J., et al. (2011) Combining Qualitative and Quantitative Evidence to Determine Factors Leading to Late Presentation for Antiretroviral Therapy in Malawi. PLoS ONE, 6, 27917. https://doi.org/10.1371/journal.pone.0027917

[18] Kwobah, C.M., Braitstein, P., Koech, J.K., Simiyu, G., Mwangi, A.W., Wools-Kaloustian, K., et al. (2015) Factors Associated with Late Engagement to HIV Care in Western Kenya A Cross-Sectional Study. Journal of the International Association of Providers of AIDS Care.

[19] Claudia Miranda, A., Moneti, V., Brogueira, P., Peres, S., Baptista, T., Aldir, I., et al. (2014) Evolution Trends over Three Decades of HIV Infection Late Diagnosis: The Experience of a Portuguese Cohort of 705 HIV-Infected Patients. Journal of the International AIDS Society, 17.

[20] Jeong, S.J., Italiano, C.M., Chaiwarith, R., Oon Tek, N., Sri La Sri Ponnampalavanar, S., Jiamsakul, A., et al. (2015) Late Presentation into Care of HIV Disease and Its Associated Factors in Asia: Results of TAHOD. AIDS Research and Human Retroviruses, 1-25.

[21] Jipa, R.E., Manea, E., Benea, S., Niculescu, I., Benea, O., Mardarescu, M., et al. (2014) Characteristics of Late Presenters in Bucharest. Journal of the International AIDS Society, 17, 19691. https://doi.org/10.7448/IAS.17.4.19691

[22] Spitzer, D.L. (2005) Engendering Health Disparities. Canadian Journal of Public Health, 96, 78-96.

[23] Mugavero, M.J., Castellano, C., Edelman, D. and Hicks, C. (2007) Late Diagnosis of HIV Infection: The Role of Age and Sex. The American Journal of Medicine, 120, 370-373.

[24] Dai, S.-Y., Liu, J.-J., Fan, Y.-G., Shan, G.-S., Zhang, H.-B., Li, M.Q., et al. (2015) Prevalence and Factors Associated with Late HIV Diagnosis. Journal of Medical Virology, 87, 970-977. https://doi.org/10.1002/jmv.24066 
[25] Buetikofer, S., Wandeler, G., Kouyos, R., Weber, R. and Ledergerber, B. (2014) Prevalence and Risk Factors of Late Presentation for HIV Diagnosis and Care in a Tertiary Referral Centre in Switzerland. Swiss Medical Weekly, 144, 13961.

[26] Wilson, K. d'Almeida, Dray-Spira, R., Aubrière, C., Hamelin, C., Spire, B., Lert, F., et al. (2014) Frequency and Correlates of Late Presentation for HIV Infection in France: Older Adults Are a Risk Group Results from the ANRS-VESPA2 Study, France. AIDS Care, 26, 83-93. https://doi.org/10.1080/09540121.2014.906554

[27] Socio-Economic Inequalities and HIV Writing Group for Collaboration of Observational HIV Epidemiological Research in Europe (COHERE) in EuroCoord, Lodi, S., Dray-Spira, R., Touloumi, G., Braun, D., Teira, R., et al. (2014) Delayed HIV Diagnosis and Initiation of Antiretroviral Therapy: Inequalities by Educational Level, COHERE in EuroCoord. AIDS (London, England), 28, 2297-2306.

[28] Kitahata, M.M., Gange, S.J., Abraham, A.G., Merriman, B., Saag, M.S., Justice, A.C., et al. (2009) Effect of Early versus Deferred Antiretroviral Therapy for HIV on Survival. The New England Journal of Medicine, 360, 1815-1826.

https://doi.org/10.1056/NEJMoa0807252 